\title{
Perbedaan Pengaruh Balanced dan Unbalanced Crystalloids sebagai Terapi Cairan pada Sepsis dan Syok Sepsis: a Systematic Review
}

\author{
Dimas Adjie Yuda Mahendra, ${ }^{1}$ Febrian Dwi Cahyo ${ }^{2}$ \\ ${ }^{1}$ Fakultas Kedokteran, Universitas Muhammadiyah Surakarta \\ ${ }^{2}$ Departemen Anestesiologi \& Terapi Intensif, Fakultas Kedokteran Universitas Muhammadiyah \\ Surakarta/RS PKU Muhammadiyah Surakarta
}

\begin{abstract}
Abstrak
Mortalitas sepsis dan syok sepsis hampir 20\% per tahun dari semua kematian global. Sepsis dan syok sepsis merupakan penyebab 50\% pasien dirawat di Intensive Care Unit (ICU). Kristaloid menjadi terapi cairan yang tepat menurut "The Surviving Sepsis Campaign Bundle: 2018 (SSC 2018)". Kristaloid terbagi menjadi dua jenis, yaitu balanced dan unbalanced crystalloids. Perbedaan kandungan elektrolit keduanya dapat memengaruhi outcome pasien. Penelitian ini bertujuan mengetahui perbedaan pengaruh balanced dan unbalanced crystalloids pada sepsis dan syok sepsis dalam aspek mortalitas, kejadian hiperkloremia, dan lama tinggal di rumah sakit (RS). Metode yang digunakan adalah systematic review. Tempat penelitian berupa pencarian artikel penelitian pada online database dengan waktu penelitian, yaitu artikel dari tahun 2017 hingga 2021. Seleksi studi menggunakan PRISMA, kirteria restriksi dan PICO. Telaah artikel didapatkan 6 dari 249 artikel yang memenuhi syarat. Hasil analisis adalah mortalitas lebih rendah pada grup balanced crystalloids, kejadian hiperkloremia lebih tinggi pada unbalanced crystalloids, namun lama tinggal di RS di kedua grup tidak ada perbedaan signifikan. Simpulan penelitian adalah balanced crystalloids lebih efektif daripada unbalanced crystalloids dalam aspek menurunkan mortalitas dan kejadian hiperkloremia, namun tidak mengenai lama tinggal.
\end{abstract}

Kata kunci: Balanced crystalloids, sepsis, syok sepsis, terapi cairan, unbalanced crystalloids

\section{Differences in the Effect of Balanced and Unbalanced Crystalloids as Fluid Therapy in Sepsis and Septic Shock: A Systematic Review}

\begin{abstract}
Sepsis and septic shock contribute to almost $20 \%$ per year to the global total deaths. Sepsis and septic shock are also the the leading causes for patients to be treated in the Intensive Care Unit (ICU), with $50 \%$ of the patients treated in this unit due to sepsis and septic shock. Crystalloid is the appropriate thereapy for these conditions according to "The Surviving Sepsis Campaign Bundle: 2018 (SSC 2018)". Crystalloids are divided into two types: balanced and unbalanced crystalloids. This study aimed to determine the difference between the effects of balanced and unbalanced crystalloids in sepsis and septic shock in terms of mortality, incidence of hyperchloremia, and length of stay in hospital. This was a systematic review on articles from the last five years using PRISMA, restriction criteria, and PICO. The review resulted in 6 out of 249 eligible articles. The results of the analysis demonstrated a lower mortality rate in the balanced crystalloids group while the incidence of hyperchloremia was higher in the unbalanced crystalloids group. No significant difference was found in the length of stay in hospital in both groups. Therefore, balanced crystalloids is more effective than unbalanced crystalloids in the aspect of reducing mortality and the incidence of hiperchloremia, with no significant difference in the length of stay in hospital.
\end{abstract}

Keywords: Balanced crystalloids, fluid therapy, sepsis, septic shock, unbalanced crystalloids

Korespondensi: Dr. Dimas Adjie Yuda Mahendra, Fakultas Kedokteran, Universitas Muhammadiyah Surakarta, Jl. Ahmad Yani, Gonilan, Kec. Kartasura, Kab. Sukoharjo, Jawa Tengah, Telp. (0271) 716844, Email j500170122@ student.ums.ac.id 


\section{Pendahuluan}

Menurut Third International Consensus Definition for sepsis (sepsis-3), cakupan sepsis terbaru terdiri atas sepsis dan syok sepsis. Sepsis adalah gangguan fungsi organ akibat respons tubuh terhadap infeksi. Syok sepsis adalah bagian dari sepsis dengan gangguan sirkulasi dan seluler/metabolik yang mengancam jiwa. ${ }^{1}$ Mortalitas sepsis dan syok sepsis hampir $20 \%$ per tahun dari semua kematian global sekaligus merupakan penyebab $50 \%$ pasien dirawat di Intensive Care Unit (ICU). ${ }^{2}$

The Surviving Sepsis Campaign Bundle: 2018 (SSC 2018) merekomendasikan pemberian terapi cairan dalam 1 jam pertama dengan kristaloid. $^{3}$ Kristaloid terbagi menjadi dua jenis, yaitu balanced crystalloids/BC (contoh: ringer laktat, plasmalyte, dan normosol) dan unbalanced crystalloids/UC (normal saline) $\mathrm{NaCl}$ 0,9\%). ${ }^{4}$ Permasalahan keduanya adalah kandungan elektrolit terutama ion klorida (BC: 92-112 mmol/L; UC: $154 \mathrm{mmol} / \mathrm{L}$ ) dan keberadaan anion organik sebagai penyangga asam-basa cairan seperti asetat, laktat, dan bikarbonat yang hanya terdapat pada BC. ${ }^{5}$ Penelitian sebelumnya menunjukkan bahwa penggunaan UC dapat menyebabkan hiperkloremia sebesar $75 \%$ pada pasien sepsis. ${ }^{6}$ Karena perbedaan kadar elektrolit pada UC dan BC maka akan memengaruhi outcome pasien sepsis dan syok sepsis.

Tujuan dan kebaruan penelitian ini adalah menegaskan pilihan terapi cairan kristaloid yang direkomendasikan SSC 2018 karena jenis kristaloid yang beragam sehingga penelitian ini dapat bermanfaat sebagai sumber informasi yang relevan dalam pemilihan cairan kristaloid yang tepat terhadap mortalitas, kejadian hiperkloremia, dan lama tinggal di rumah sakit pada pasien sepsis dan syok sepsis.

\section{Subjek dan Metode}

Desain penelitian ini adalah systematic review. Subjek penelitian berupa artikel penelitian di seluruh dunia dengan pencarian pada online database, yaitu PubMed, Science direct, dan Research gate dengan kata kunci: ("balanced crystalloids" OR "ringer's lactat") AND ("normal saline" OR "saline solution" OR "unbalanced crystalloids") AND ("fluid therapy" OR "fluid resuscitation") AND (sepsis OR "septic shock").

Seleksi artikel menggunakan metode PRISMA (Preferred Reporting Items for Systematic Reviews and Meta-analyses) dengan memenuhi syarat sesuai kriteria restriksi dan PICO (Problem Intervention Comparison Outcome.$^{7}$ Kriteria inklusi, yaitu populasi/ sampel berusia $>18$ tahun dengan diagnosis sepsis/syok sepsis; intervensi menggunakan balanced crystalloids, seperti ringer laktat, plasmalyte, dan normosol; kontrol
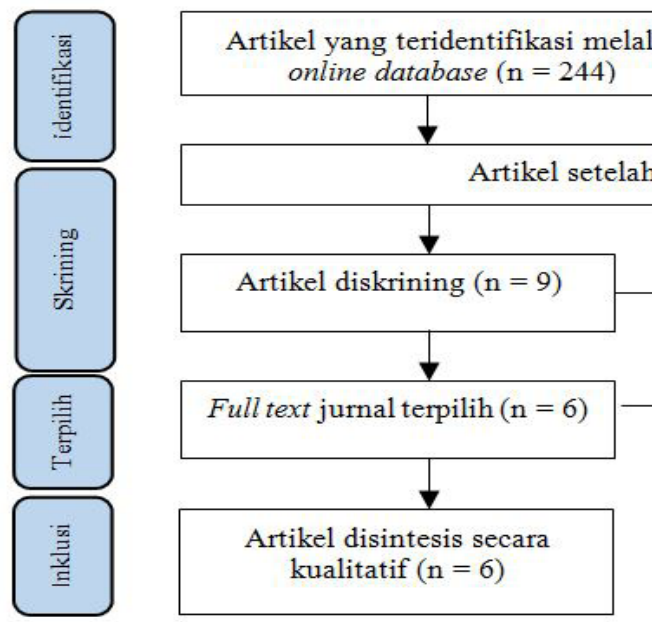

\section{Gambar PRISMA Flow Chart}


Tabel 1 Ekstraksi Data

\begin{tabular}{|c|c|c|c|c|c|}
\hline $\begin{array}{l}\text { Penulis \& } \\
\text { Tahun }\end{array}$ & Desain Studi & Sampel & $\begin{array}{c}\text { Senter } \\
\text { Penelitian }\end{array}$ & $\begin{array}{c}\text { Intervensi } \\
\text { dengan } \\
\text { Kontrol UC } \\
\end{array}$ & Outcome \\
\hline $\begin{array}{l}\text { Brown dkk. } \\
2019\end{array}$ & RCT & 1.641 & 5 & $\begin{array}{l}\text { RL atau } \\
\text { Plasma-Lyte A }\end{array}$ & $\begin{array}{l}\text { Mortalitas } \\
\text { Kejadian hiperkloremia }\end{array}$ \\
\hline $\begin{array}{l}\text { Duffy dkk. } \\
2019\end{array}$ & $\begin{array}{l}\text { Kohort } \\
\text { retrospektif }\end{array}$ & 1.218 & 1 & Normosol & $\begin{array}{l}\text { Mortalitas } \\
\text { Kejadian hiperkloremia } \\
\text { Lama tinggal di RS }\end{array}$ \\
\hline $\begin{array}{l}\text { Golla dkk. } \\
2020\end{array}$ & RCT & 160 & 1 & RL & $\begin{array}{l}\text { Mortalitas } \\
\text { Kejadian hiperkloremia }\end{array}$ \\
\hline $\begin{array}{l}\text { Jackson } \\
\text { dkk. }{ }^{11} 2020\end{array}$ & RCT & 1.274 & 2 & $\begin{array}{l}\text { RL atau } \\
\text { Plasma-Lyte A }\end{array}$ & Mortalitas \\
\hline $\begin{array}{l}\text { Semler } \\
\text { dkk. }^{12} 2018\end{array}$ & RCT & 2.336 & 5 & $\begin{array}{l}\text { RL atau } \\
\text { Plasma-Lyte A }\end{array}$ & Mortalitas \\
\hline $\begin{array}{l}\text { Sethi dkk. }{ }^{13} \\
2018\end{array}$ & $\begin{array}{l}\text { Case control } \\
\text { retrospektif }\end{array}$ & 115 & 1 & $\begin{array}{l}\text { RL dan } \\
\text { kombinasi RL } \\
+ \text { NS }\end{array}$ & $\begin{array}{l}\text { Mortalitas } \\
\text { Lama tinggal di RS }\end{array}$ \\
\hline
\end{tabular}

Keterangan: NS: normal saline; RCT: randomized controlled trial; RL: ringer laktat; RS: rumah sakit; UC: unbalanced crystalloids

menggunakan unbalanced crystalloids yaitu normal saline $/ \mathrm{NaCl} 0,9 \%$. Outcome mencakup mortalitas, kejadian hiperkloremia, dan lama tinggal di rumah sakit; desain studi yang dipilih sebagai sumber data adalah randomized contolled trials (RCT) dan studi observasional analitik; artikel berbahasa Inggris atau Indonesia dengan limitasi 5 tahun terakhir, yaitu dari tahun 2015 sampai 2020. Kriteria eksklusi, yaitu penelitian yang menggunakan perbandingan koloid dan kristaloid; penelitian dengan subjek penyakit kritis selain sepsis \&

Tabel 2 Penilaian Quality of Evidence dengan GRADE

\begin{tabular}{|c|c|c|c|c|c|c|}
\hline \multirow[b]{2}{*}{ Penilaian } & \multicolumn{6}{|c|}{ Penulis \& Tahun } \\
\hline & $\begin{array}{l}\text { Brown. } \\
\text { dkk. }{ }^{9} \\
2019\end{array}$ & $\begin{array}{c}\text { Duffy } \\
\text { dkk. }^{10} \\
2019\end{array}$ & $\begin{array}{l}\text { Golla } \\
\text { dkk. }^{6} \\
2020\end{array}$ & $\begin{array}{c}\text { Jackson } \\
\text { dkk.11 } \\
2020\end{array}$ & $\begin{array}{c}\text { Semler } \\
\text { dkk. }^{12} \\
2018\end{array}$ & $\begin{array}{c}\text { Sethi } \\
\text { dkk. }^{13} \\
2018\end{array}$ \\
\hline Grade awal & Tinggi & Rendah & Tinggi & Tinggi & Tinggi & Rendah \\
\hline \multicolumn{7}{|l|}{ Faktor downgrade } \\
\hline Risiko bias & + & - & - & + & + & - \\
\hline inkonsistensi & - & - & - & - & - & - \\
\hline Bukti tak langsung & - & - & - & - & - & - \\
\hline Impresisi & - & - & - & - & - & - \\
\hline Bias publikasi & - & - & - & - & - & - \\
\hline \multicolumn{7}{|l|}{ Faktor upgrade } \\
\hline Efek besar & - & - & - & - & - & - \\
\hline Respons dosis & + & + & - & - & + & + \\
\hline Perancu & + & - & - & + & - & - \\
\hline Grade akhir & Tinggi & Sedang & Tinggi & Tinggi & Tinggi & Sedang \\
\hline
\end{tabular}


Tabel 3 Karakteristik Data

\begin{tabular}{|c|c|c|c|c|}
\hline \multirow{2}{*}{$\begin{array}{l}\text { Penulis } \\
\text { \& Tahun }\end{array}$} & \multirow{2}{*}{ GRADE } & \multirow{2}{*}{ Intervensi/paparan } & \multicolumn{2}{|c|}{ Jumlah Pasien } \\
\hline & & & BC & UC \\
\hline $\begin{array}{l}\text { Brown } \\
\text { dkk. } \\
2019\end{array}$ & Tinggi & $\begin{array}{l}\text { Merupakan analisis sekunder RCT dari penelitian } \\
\text { Semler dkk. }{ }^{12}\end{array}$ & $\begin{array}{l}\text { RL atau } \\
\text { Plasma-Lyte } \\
A(\mathrm{n}=824)\end{array}$ & NS $(n=817)$ \\
\hline $\begin{array}{l}\text { Duffy } \\
\text { dkk. }^{10} \\
2019\end{array}$ & Sedang & $\begin{array}{l}\text { Pengamatan "before-after cohort" untuk } \\
\text { mengetahui perbedaan outcome } \\
\text { Pengataman before, yaitu grup yang menerima NS } \\
\text { sebanyak minimal } 2 \text { L sampai hari ketiga dilakukan } \\
\text { tahun } 2014 \\
\text { Pengamatan after, yaitu grup yang menerima } \\
\text { normosol minimal 2 L sampai hari ketiga } \\
\text { dilakukan tahun } 2015\end{array}$ & $\begin{array}{l}\text { Normosol } \\
(n=680)\end{array}$ & NS $(n=538)$ \\
\hline $\begin{array}{l}\text { Golla } \\
\text { dkk. } \\
2020\end{array}$ & Tinggi & $\begin{array}{l}\text { Pasien diberikan terapi cairan sesuai grup dengan } \\
\text { follow up } 12 \text { jam, } 24 \text { jam, dan } 48 \text { jam. } \\
\text { Jumlah cairan pada grup NS adalah } 3,66 \pm 0,79 \mathrm{~L} \\
\text { Jumlah cairan pada grup RL adalah } 3,74 \pm 0,92 \mathrm{~L}\end{array}$ & $\operatorname{RL}(n=80)$ & NS $(n=80)$ \\
\hline $\begin{array}{l}\text { Jackson } \\
\text { dkk. }^{11} \\
2020\end{array}$ & Tinggi & $\begin{array}{l}\text { Merupakan analisis sekunder RCT dari penelitian } \\
\text { Semler dkk. }{ }^{12} \\
\text { Penelitian ini menganalisis outcome ketika } \\
\text { intervensi dilakukan lebih awal saat di ED }\end{array}$ & $\begin{array}{l}\text { RL atau } \\
\text { Plasma-Lyte } \\
A(\mathrm{n}=682)\end{array}$ & NS (n=592) \\
\hline $\begin{array}{l}\text { Semler } \\
\text { dkk. }^{12} \\
2018\end{array}$ & Tinggi & $\begin{array}{l}\text { Jumlah cairan pada grup RL atau plasma-lyte } A \\
\text { adalah } 1281 \pm 67 \mathrm{~mL} \text { dalam } 24 \text { jam } \\
\text { Jumlah cairan pada grup NS adalah } 1.262 \pm 59 \mathrm{~mL} \\
\text { dalam } 24 \text { jam }\end{array}$ & $\begin{array}{l}\mathrm{RL} \text { atau } \\
\text { Plasma-Lyte } \\
A(\mathrm{n}=1.147)\end{array}$ & NS $(n=1.169)$ \\
\hline $\begin{array}{l}\text { Sethi } \\
\text { dkk }^{13} \\
2018\end{array}$ & Sedang & $\begin{array}{l}\text { Data penelitian diambil dari data pasien sepsis di } \\
\text { ED } \\
\text { Pemberian terapi cairan dilakukan oleh dokter } \\
\text { yang bertugas di ED selama } 48 \text { jam }\end{array}$ & $\begin{array}{l}R L(n=6) \\
R L+N S \\
(n=61)\end{array}$ & NS $(n=48)$ \\
\hline
\end{tabular}

Keterangan: BC: balanced crystalloids; ED: emergency department; NS: normal saline; RCT: randomized controlled trial; RL: ringer laktat; UC: unbalanced crystalloids

syok sepsis.

Langkah analisis data, yaitu melakukan ekstraksi data artikel yang telah memenuhi syarat, kemudian dilakukan penilaian quality of evidence menggunakan GRADE (Grading of Recommendations, Assessment, Development, and Evaluations) oleh kedua penulis sesuai panduan ${ }^{8}$ dan menganalisisnya secara kualitatif (naratif). Penelitian ini telah mendapatkan persetujuan Komite Etik Penelitian Kesehatan Fakultas Kedokteran Universitas Muhammadiyah Surakarta dengan Nomor: 3159/C.1/KEPK-FKUMS/XI/2020.

\section{Hasil}

Proses seleksi dan pencarian artikel menggunakan PRISMA flow chart seperti pada
Gambar. Dari 249 artikel hasil pencarian online database, terdapat 6 jurnal yang memenuhi syarat dilakukan ekstraksi data pada Tabel 1.

Untuk menilai kualitas artikel setelah ekstraksi data maka dilakukan penilaian quality of evidence menggunakan GRADE (Grading of Recommendations, Assessment, Development, and Evaluations) seperti pada Tabel 2. GRADE digunakan oleh systematic reviewers dan guideline developers untuk menilai kualitas bukti dan merekomendasikan suatu intervensi. ${ }^{8}$ Hasil akhir penilaian terdapat empat artikel dengan kualitas tinggi dan dua artikel dengan kualitas sedang.

Karakteristik data (Tabel 3) menjelaskan tentang intervensi atau paparan terhadap subjek penelitian, yaitu pasien sepsis dan syok sepsis. Jenis terapi cairan dan jumlah pasien 
Tabel 4 Analisis Outcome

\begin{tabular}{|c|c|c|c|c|}
\hline \multirow{2}{*}{ Outcome } & \multirow{2}{*}{$\begin{array}{l}\text { Penulis \& } \\
\text { Tahun }\end{array}$} & \multicolumn{2}{|c|}{ Kejadian/Total } & \multirow{2}{*}{ Hasil } \\
\hline & & BC & UC & \\
\hline \multirow[t]{6}{*}{ Mortalitas $^{\mathrm{a}}$} & Brown $2019^{7}$ & $217 / 824$ & $255 / 817$ & $\mathrm{p}=0.01 ;$ OR: $0.74 ; 95 \%$ CI [0.59-0.93] \\
\hline & Duffy $2019^{8}$ & $66 / 680$ & $68 / 538$ & $\mathrm{p}=0.77$ \\
\hline & Golla $2020^{6}$ & $29 / 80$ & $35 / 80$ & $p=0.418$ \\
\hline & Jackson $2020^{9}$ & $170 / 682$ & $181 / 592$ & OR: $0.68 ; 95 \%$ CI [0.52-0.89] \\
\hline & Semler $2018^{10}$ & $395 / 1.147$ & $455 / 1.169$ & $\mathrm{p}=0.02 ;$ OR: $0.80 ; 95 \%$ CI [0.67-0.97] \\
\hline & Sethi $2018^{11}$ & $\begin{array}{l}\text { Tidak } \\
\text { dilaporkan }\end{array}$ & $\begin{array}{l}\text { Tidak } \\
\text { dilaporkan }\end{array}$ & $\begin{array}{l}\mathrm{p}=0.00003 ; \text { OR: } 0.973 ; 95 \% \text { CI }[0.961- \\
0.986]\end{array}$ \\
\hline \multirow{3}{*}{$\begin{array}{l}\text { Kejadian } \\
\text { hiperkloremia }^{\mathrm{b}}\end{array}$} & Brown $2019^{7}$ & $300 / 816^{*}$ & $374 / 806^{*}$ & $\mathrm{p}<0.001$ \\
\hline & Duffy $2019^{8}$ & $89 / 680$ & $148 / 538$ & $\mathrm{p}<0.0001 ; \mathrm{RR}: 0.41$ \\
\hline & Golla $2020^{6}$ & $39 / 80$ & $60 / 80$ & $\mathrm{p}=0.001$ \\
\hline \multirow{2}{*}{$\begin{array}{l}\text { Lama tinggal } \\
\text { di RS }^{\mathrm{c}}\end{array}$} & Duffy $2019^{8}$ & 7.9 & 8.4 & $p=0.47$ \\
\hline & Sethi $2018^{11}$ & $\begin{array}{l}\text { Tidak } \\
\text { dilaporkan }\end{array}$ & $\begin{array}{l}\text { Tidak } \\
\text { dilaporkan }\end{array}$ & $p=0.066$ \\
\hline
\end{tabular}

Keterangan: a: mortalitas dalam 30 hari; b: kadar sodium $\geq 110 \mathrm{mmol} / \mathrm{L}$; : dalam satuan hari; *: tidak tercatat data sebanyak 8 pasien pada BC dan 11 pada UC;BC: Balanced Crystalloids; CI: Confidence Interval; OR: Odds Ratio; RR: Risk Ratio; RS: Rumah Sakit; UC: Unbalanced Crystalloids.

juga dijelaskan dalam karakteristik data.

Analisis outcome (Tabel 4) membandingkan perbedaan hasil outcome berdasar atas kualitas (GRADE) artikel supaya sebanding. Terdapat keterbatasan pada penelitian Golla dkk. ${ }^{6}$ sehingga hasil mortalitas tidak signifikan $(p=0,418)$ dibandingkan penelitian Semler $\mathrm{dkk}^{12}(\mathrm{p}=0,02)$. Jumlah pasien pada penelitian Golla dkk. ${ }^{6}$ sangat sedikit, yaitu 160 pasien dibanding dengan Semler dkk. ${ }^{12}$ dengan 2.336 pasien dan jumlah senter penelitian Golla dkk. ${ }^{6}$ hanya satu dibanding dengan Semler dkk. ${ }^{12}$ yang berjumlah lima senter. Oleh karena itu, hasil mortalitas lebih relevan pada penelitian Semler dkk. ${ }^{12}(p=0,02)$. Penelitian Duffy dkk. ${ }^{10}$ juga menyatakan mortalitas tidak signifikan $(\mathrm{p}=0,77)$, terdapat keterbatasan jika dibanding dengan penelitian Sethi dkk. ${ }^{13}(p=0,00003)$, yaitu Duffy dkk. ${ }^{10}$ mengeksklusi pasien sepsis dan syok sepsis dengan komorbid sedangkan Sethi dkk. ${ }^{13}$ tidak demikian. Penelitian Duffy dkk. ${ }^{10}$ kurang relevan karena tidak dapat menyamaratakan kondisi sepsis dan syok sepsis pada populasi.

Hasil analisis kejadian hiperkloremia pada tiga artikel, yaitu Golla dkk. ${ }^{6}$, Brown dkk. ${ }^{9}$, dan
Duffy dkk. ${ }^{10}$ semuanya menyatakan signifikan kejadian hiperkloremia pada grup UC dibanding dengan BC. Outcome lama tinggal di RS pada dua artikel, yaitu Sethi dkk. ${ }^{13}$ dan Duffy dkk. ${ }^{10}$ menyatakan tidak signifikan ( $\mathrm{p}=0,066$ dan $\mathrm{p}=0,47)$ meskipun lama tinggal di RS lebih lama pada grup UC dibanding dengan $\mathrm{BC}(8,4: 7,9)$.

\section{Pembahasan}

Analisis data dilakukan secara kualitatif/ naratif sesuai dengan langkah-langkah protokol systematic review. Langkah pertama adalah seleksi artikel menggunakan PRISMA flow chart (Gambar) sesuai dengan kata kunci pencarian berdasar atas kriteria restriksi dan PICO. Setelah mendapatkan enam dari 249 artikel, selanjutnya dilakukan ekstraksi data yang memuat informasi umum penelitian (Tabel 1). Langkah kedua, yaitu menilai kualitas artikel dengan penilaian GRADE karena hal tersebut akan menjadi parameter penilaian pada analisis secara kualitatif (Tabel 2). Kualitas akhir berguna untuk membandingkan hasil penelitian pada 
beberapa artikel dengan kualitas akhir yang sama agar sebanding. Langkah selanjutnya, yaitu memaparkan karakteristik data penelitian yang memuat intervensi/paparan dan jumlah sampel penelitian tiap kelompok intervensi maupun kontrol. Langkah terakhir adalah analisis outcome berdasar atas hasil nilai p, OR, RR, dan 95\% CI.

Analisis outcome mortalitas (Tabel 4) terdapat hasil yang beragam, empat dari enam data menyatakan signifikan sedangkan dua di antaranya tidak. Oleh karena itu, dilakukan kajian untuk mendapatkan hasil akhir analisis outcome mortalitas. Beberapa keterbatasan penelitian dapat memengaruhi hasil penelitian seperti jumlah sampel yang sedikit, jumlah senter penelitian, dan mengeksklusi pasien dengan komorbid. Keterbatasan tersebut maka hasil penelitian menjadi kurang relevan. Analisis pertama, yaitu membandingkan hasil penelitian Golla dkk. ${ }^{6}$ dengan Semler dkk. ${ }^{12}$ yang keduanya memiliki kualitas akhir tinggi. Terdapat keterbatasan pada penelitian Golla dkk. ${ }^{6}$ sehingga hasil mortalitas tidak signifikan $(\mathrm{p}=0,418)$ dibanding dengan penelitian Semler dkk. ${ }^{12}$ ( $\mathrm{p}=0,02$; OR: 0,80; 95\% CI [0,67$0,97])$. Keterbatasan tersebut adalah jumlah pasien pada penelitian Golla sangat sedikit, yaitu 160 pasien dibanding dengan Semler dkk. $^{12}$ dengan 2.336 pasien dan jumlah senter penelitian Golla dkk. ${ }^{6}$ hanya satu dibanding dengan Semler dkk. ${ }^{12}$ yang berjumlah lima senter. Dinyatakan mortalitas lebih relevan pada penelitian Semler dkk. ${ }^{12}(p=0,02)$.

Penelitian Duffy dkk. ${ }^{10}$ juga menyatakan mortalitas tidak signifikan $(\mathrm{p}=0,77)$ dibanding dengan penelitian Sethi dkk. ${ }^{13}(\mathrm{p}=0,00003$; OR: $\quad 0,973 ; \quad 95 \% \quad$ CI $\quad[0,961-0,986])$. Keterbatasan penelitian Duffy dkk. ${ }^{10}$ adalah mengeksklusi pasien sepsis dan syok sepsis dengan komorbid, sedangkan Sethi dkk. ${ }^{13}$ tidak demikian. Dengan demikian, penelitian Duffy dkk. ${ }^{10}$ kurang relevan karena tidak dapat menyamaratakan kondisi sepsis dan syok sepsis pada populasi. Analisis berikutnya adalah penelitian Brown dkk. ${ }^{9}$ dan Jackson dkk. ${ }^{11}$ yang merupakan analisis sekunder dari penelitian Semler dkk. ${ }^{12}$ dengan melakukan restriksi jumlah pasien dari 2.336 menjadi
1.641 orang. Brown dkk. ${ }^{9}$ menganalisis pemberian terapi cairan di ICU saja $(p=0,01$; OR: 0,$74 ; 95 \%$ CI $[0,59-0,93])$, sedangkan Jackson dkk. ${ }^{11}$ menganalisis pemberian terapi cairan lebih awal saat pasien diterima di ED dilanjutkan sampai ICU (OR: 0,68).

Hasil analisis tiga artikel, yaitu Golla dkk. ${ }^{6}$, Brown dkk. ${ }^{9}$, dan Duffy dkk. ${ }^{10}$ menyatakan signifikan kejadian hiperkloremia pada grup UC dibanding dengan BC. Golla memakai ringer laktat sebagai BC kemudian setelah 24 jam dirandomisasi, kejadian hiperkloremia dengan definisi kadar ion klorida dalam darah sebesar $\geqslant 110 \mathrm{mEq} / \mathrm{L}$ pada grup UC lebih tinggi dibanding dengan grup BC (75\%:48,8\%) dengan nilai $\mathrm{p}=0,001$. Pada penelitian Duffy dkk. ${ }^{10}$ terdapat perbedaan pada cairan BC yang dipakai, yaitu memakai normosol, walaupun begitu tetap hasil kejadian hiperkloremia signifikan lebih tinggi pada grup UC setelah 72 jam pengamatan dengan nilai $\mathrm{p}<0,0001$.

Outcome lama tinggal di RS/length of stay (LOS) hanya terdapat pada dua artikel yaitu Sethi dkk. ${ }^{13}$ dan Duffy dkk. ${ }^{10}$. Hasil keduanya menunjukkan LOS antara BC dan UC tidak ada perbedaan yang signifikan $(\mathrm{p}=0,066$ dan $\mathrm{p}=0,47)$. Meskipun tidak signifikan, tetapi lama tinggal di RS lebih lama pada grup UC dibandingkan BC $(8,4: 7,9)$.

Masalah utama pada sepsis dan syok sepsis adalah perfusi jaringan perifer berkurang dikarenakan volume intravaskular yang menurun. Penurunan ini karena berkurangnya oral intake, vasodilatasi, disfungsi endotel, dan kebocoran kapiler pembuluh darah. Terapi cairan dengan kristaloid diharapkan dapat meningkatkan preload jantung yang juga akan meningkatkan cardiac output. Peningkatan cardiac output akan meningkatkan penyampaian oksigen ke jaringan perifer dan hipoksia dapat teratasi ${ }^{14}$

Kristaloid jenis unbalanced crystalloids (UC) yaitu normal saline (NS) memiliki konsentrasi ion klorida sebesar $154 \mathrm{mmol} / \mathrm{L}$ yang lebih tinggi sekitar $50 \%$ daripada konsentrasi ion klorida cairan ekstraseluler dan tidak memiliki anion organik sebagai penyangga asam-basa cairan. ${ }^{14}$ Kadar ion klorida yang tinggi atau hiperkloremia akan mengubah nilai strong 
ion difference (SID) menjadi di bawah normal SID plasma. Nilai SID didapatkan dari selisih kation dengan anion suatu larutan. Normal SID pada cairan ekstraseluler manusia adalah 40$44 \mathrm{mEq} / \mathrm{L}$, sedangkan UC memiliki nilai SID sebesar $0 \mathrm{mEq} / \mathrm{L}$. Apabila nilai SID di bawah normal akan bersifat asidemia sehingga akan menjadi asidosis metabolik hiperkloremik. ${ }^{15}$

Hiperkloremia pada pasien sepsis dan syok sepsis akibat terapi cairan menggunakan UC terbukti signifikan dengan nilai $\mathrm{p}=0,001{ }^{6}$ Hiperkloremia akan menyebabkan penurunan perfusi ke ginjal yang berakibat acute kidney injury (AKI). Secara tidak langsung AKI akan menyebabkan peningkatan mortalitas pada pasien sepsis dan syok sepsis. ${ }^{10}$ Hal tersebut terbukti bahwa terapi cairan dengan UC dibanding dengan $\mathrm{BC}$ meningkatkan mortalitas pasien sepsis dan syok sepsis dengan nilai $\mathrm{p}=0,02 .{ }^{12}$ Kemudian, penggunaan cairan balanced crystalloids (BC) akan memberi perbaikan hemodinamik pada pasien sepsis dan syok sepsis lebih aman karena kadar ion klorida yang mirip dengan plasma sehingga dapat dihubungkan dengan lama tinggal di rumah sakit. Pada penelitian Golla dkk. ${ }^{6}$ grup dengan paparan normosol yang termasuk BC dibanding dengan grup UC terhadap lama tinggal di RS hasilnya lebih singkat (7,9 hari:8,4 hari). Walaupun grup UC lebih lama dalam lama tinggal di RS, namun hubungan kedua grup tidak signifikan. ${ }^{10}$ Sethi dkk. ${ }^{13}$ menyatakan ketidaksignifikan terjadi karena kondisi komorbid pasien yang berbeda-beda, sehingga dibutuhkan penelitian RCT dengan membuat sub-grup sesuai komorbid yang mendasari karena terdapat risiko ketika merestriksi UC pada pasien dengan hiponatremia, alkalemia, edema serebral, dan cedera otak. ${ }^{13}$

Keterbatasan penelitian ini adalah tidak dilakukan analisis kuantitatifatau metaanalisis sehingga kurang mendapatkan hasil analisis data yang lebih akurat. Adapun kelebihan penelitian ini, yaitu metode systematic review berada pada puncak evidence based medicine sehingga dapat menjadi sumber bukti klinis yang relevan dan penelitian ini telah memenuhi kaidah sesuai dengan protokol systematic review. ${ }^{7}$
Saran untuk penelitian selanjutnya adalah melakukan penelitian RCT dengan sampel lebih banyak dan tidak mengeksklusi pasien sepsis dan syok sepsis dengan komorbid sehingga dapat menyamaratakan ke tingkat populasi sebenarnya.

\section{Simpulan}

Penggunaan terapi cairan balanced crystalloids (ringer laktat, plasmalyte, dan normosol) dibanding dengan unbalanced crystalloids (normal saline) pada pasien sepsis dan syok sepsis lebih efektif dalam menurunkan mortalitas dan kejadian hiperkloremia, namun tidak efektif untuk lama tinggal di rumah sakit.

\section{Daftar Pustaka}

1. Rhodes A, Evans LE, Alhazzani W, Levy MM, Antonelli M, Ferrer R, dkk. Surviving Sepsis Campaign: International Guidelines for Management of Sepsis and Septic Shock. Crit Care Med. : 2016;45:486-552.

2. Kempker JA, Martin GS. A global accounting of sepsis. Lancet [Internet]. 2020;395(10219):168-70 (diunduh 20 febuari 2021). Tersedia dari: http://dx.doi. org/10.1016/S0140-6736(19)33065-X.

3. Levy MM, Evans LE, Rhodes A. The Surviving Sepsis Campaign Bundle: 2018 update. Intens Care Med [Internet]. 2018;44(6):925-8 (diunduh 20 febuari 2021). Tersedia dari: https://doi. org/10.1007/s00134-018-5085-0.

4. MacDonald N, Pearse RM. Are we close to the ideal intravenous fluid? Br J Anaesth [Internet]. 2017;119:i63-71 (diunduh 15 Januari 2021). Tersedia dari: http:// dx.doi.org/10.1093/bja/aex293.

5. Semler MW, Kellum JA. Balanced crystalloid solutions. Am J Respir Crit Care Med. 2019;199(8):952-60.

6. Golla R, Kumar S, Dhibhar DP, Bhalla A, Sharma N. 0.9\% saline V/S Ringer's lactate for fluid resuscitation in adult sepsis patients in emergency medical services: An open-label randomized controlled trial. Hong Kong J Emerg Med. 2020;1(1):1-9. 
7. Linares-Espinós E, Hernández V, Domínguez-Escrig JL, Fernández-Pello S, Hevia V, Mayor J, dkk. Methodology of a systematic review. Actas Urológicas Españolas (English Ed [Internet]. 2018;42(8):499-506 (diunduh tanggal 12 Januari 2021). Tersedia dari: http:// dx.doi.org/10.1016/j.acuroe.2018.07.002.

8. Balshem $H$, Helfand $M$, Schünemann $H J$, Oxman AD, Kunz R, Brozek J, dkk. GRADE guidelines: 3 . Rating the quality of evidence. J Clin Epidemiol. 2011;64(4):401-6.

9. Brown RM, Wang L, Coston TD, Krishnan NI, Casey JD, Wanderer JP, dkk. Balanced crystalloids versus saline in sepsis: a secondary analysis of the SMART clinical trial. Am J Respir Crit Care Med. 2019;200(12):1487-95.

10. Duffy RA, Foroozesh MB, Loflin RD, Ie SR, Icard BL, Tegge AN, dkk. Normal saline versus Normosol $^{\mathrm{TM}}$ - $\mathrm{R}$ in sepsis resuscitation: a retrospective cohort study. J Intensive Care Soc [Internet]. 2019; 20(3):223-30 (diunduh tanggal 15 Febuari 2021). Tersedia dari: https://doi. org/10.1177/1751143718786113.

11. Jackson KE, Wang L, Casey JD, Bernard GR, Self WH, Rice TW, dkk. Effect of early balanced crystalloids before icu admission on sepsis outcomes. Chest [Internet]. 2020 (diunduh tanggal 11 Febuari 2021). Tersedia dari: https://doi.org/10.1016/j. chest.2020.08.2068.

12. Semler MW, Self WH, Wanderer JP, Ehrenfeld JM, Wang L, Stollings JL, dkk. Balanced crystalloids versus saline in critically ill adults. $\mathrm{N}$ Engl J Med. 2018;12(1):152-63.

13. Sethi M, Owyang CG, Meyers C, Parekh R, Shah KH, Manini AF. Choice of resuscitative fluids and mortality in emergency department patients with sepsis. Am J Emerg Med [Internet]. 2018;36(4):625-9 (diunduh 20 Desember 2020). Tersedia dari: http://dx.doi.org/10.1016/j.ajem. 2017.09.042

14. Brown RM, Semler MW. Fluid management in sepsis. J Intens Care Med. 2019; 34(5):364-73.

15. Ali Rahman F, Fitriani Retno W, Calcarina, Yudo Pratomo B. Aplikasi klinis analisis gas darah pendekatan stewart pada periode perioperatif. J Komplikasi Anestesi [Internet]. 2015;3(November):69-80 (diunduh 15 Desember 2020). Tersedia dari: http://anestesi.fk.ugm.ac.id/jka.ugm /download-file-948305.pdf. 